\title{
Implementasi Sistem Data Mining Untuk Menentukan Stock Accuracy Pada Warehouse PT Coca-Cola Amatil Indonesia Cibitung-Plant
}

\author{
Hendarman Lubis, Dwi Budi Srisulistiowati \\ Fakultas Teknik, Program Studi Teknik Informatika, Universitas Bhayangkara Jakarta Raya, Indonesia \\ Email: 1,"hendarman.lubis@dsn.ubharajaya.ac.id, 2dwibudi@dsn.ubharajaya.ac.id \\ ${ }^{*}$ Email Penulis Korespondensi: hendarman.lubis@dsn.ubharajaya.ac.id
}

\begin{abstract}
Abstrak-Data Mining merupakan suatu proses penggalian data atau penyaringan data yang memanfaatkan kumpulan data dengan ukuran yang besar melalui serangkaian proses untuk mendapatkan informasi yang berharga dari data tersebut. PT. Coca-Cola Amatil Indonesia Cibitung-Plant memiliki salah satu gudang terbesar di Indonesia tepatnya Warehouse Mega Distribution Center (DC), dengan luas gudang $\pm 32000 \mathrm{~m} 2$ atau setara dengan \pm 30000 Pallet. Untuk menjaga keakuratan stok di warehouse tentunya diperlukan suatu sistem yang baik agar dapat menunjang kegiatan operasional di dalam warehouse, salah satu cara untuk menjaga keakuratan stok di dalam warehouse yaitu dengan melakukan penghitungan produk secara keseluruhan di dalam warehouse (Stock Opname), agar dapat diketahui keakuratan data di dalam sistem dengan stok fisik yang ada di gudang. Dengan adanya data transaksi yang tersimpan dalam basis data, terkadang data transaksi tersebut hanya dibiarkan menumpuk tanpa ada tindakan yang lebih lanjut, maka dibuatkannya sistem informasi yang mengolah data tersebut untuk menggali informasi dengan teknik data mining.
\end{abstract}

Kata Kunci: Data Mining, Stock Opname, Warehouse.

Abstract-Data Mining is a process of extracting data or filtering data that utilizes large data sets through a series of processes to obtain information that stands out from the data. PT. Coca-Cola Amatil Indonesia Cibitung-Plant has one of the largest warehouse in Indonesia exactly warehouse mega distribution center (DC). With $\pm 32000 \mathrm{~m} 2$ warehouse area or equivalent to \pm 30000 Pallets. To maintain the accuracy of the stock in the warehouse of course required a good system in order to support the operational activities in the warehouse, one way to maintain the accuracy of stock in the warehouse is to do the overall product calculation in the warehouse (Stock Opname), in order to know the accuracy data in the system with the physical stock in the warehouse. With the data transactions stored in the database, sometimes the transaction data is only on leave to accumulate without any further action, then make the information system that manages the data to dig information by data mining techniques.

Keywords: Data Mining, Stock Opname, Warehouse.

\section{PENDAHULUAN}

PT.Coca-Cola Amatil Indonesia merupakan sebuah perusahaan manufacture yang bergerak dibidang minuman ringan terkemuka di Indonesia. Perusahaan ini memproduksi berbagai macam minuman ringan dibawah lisensi perusahaan The Coca-Cola Company yang berpusat di Atlanta, dimana perusahaan ini memiliki salah satu gudang terbesar di Indonesia tepatnya Warehouse Mega Distribution Center (DC) di Cibitung - Bekasi, dengan luas gudang $\pm 32000 \mathrm{~m} 2$ atau setara dengan \pm 30000 Pallet. Untuk menjaga keakuratan stok di warehouse tentunya diperlukan suatu sistem yang baik agar dapat menunjang kegiatan operasional di dalam warehouse. Salah satu cara untuk menjaga keakuratan stok di dalam warehouse yaitu dengan melakukan penghitungan produk secara keseluruhan di dalam warehouse (Stock take full count), agar dapat diketahui keakuratan data di dalam sistem dengan stok fisik yang ada di gudang. Stock Take Full Count adalah proses penghitungan stok produk yang ada digudang secara manual dengan acuan data yang di download dari sistem. Proses stock count ini biasanya dilakukan dalam satu bulan (Mounthly Stock Count), untuk proses Monthly stock count dibutuhkan penghitung minimal 24 orang, setiap orang akan menghitung produk sesuai lokasi atau blok yang sudah ditentukan oleh team inventory control, dalam proses penghitungan produk lebih baik dilakukan dihari libur agar kegiatan operasional warehouse tidak terganggu. Impact terhadap kegiatan operasional adalah semua aktifitas warehouse baik secara sistem ataupun pergerakan barang secara fisik tidak boleh dilakukan apapun alasannya. Hasil perhitungan ini yang nantinya akan dibandingkan oleh team inventory control dengan total stok yang ada di sistem. jika semua penghitungan produk di warehouse telah selesai dan sudah selesai diinput di sistem oleh team inventory control maka ditemukan hasilnya, dan hasil tersebut akan langsung di follow-up oleh manager untuk proses pengambilan keputusan, misalnya sudah ditemukan selisih jumlah total produk dari hasil perhitungan fisik dengan sistem

yang ada. Apabila sudah diambil keputusan oleh Manager terhadap perlakuan difference

yang muncul setelah penghitungan produk dilakukan, maka yang akan dilakukan oleh team inventory control adalah menyamakan (Adjustment) stok fisik dengan yang ada di sistem, dan tentunya dilanjutkan dengan pembuatan laporan inventory losess. Dengan adanya data transaksi yang tersimpan dalam basis datanya, terkadang data transaksi tersebut hanya dibiarkan menumpuk tanpa ada tindakan yang lebih lanjut, maka peran dalam mengambil keputusan untuk menganalisis secara manual perlu digantikan dengan sistem informasi yang lebih akurat, sehingga proses dalam pengambilan keputusan dapat dilakukan secara otomatis dan lebih mudah. Untuk mendapatkan hasil stock opname yang lebih akurat maka metode yang digunakan dalam sistem data mining adalah dengan menggunakan metode clustering, dengan mengelompokkan sejumlah data/obyek ke dalam 
cluster (group) diantaranya kode produk, kemasan produk, serta jumlah produk, dimana semua obyek dikelompokan dalam satu cluster, hal ini berfungsi untuk menentukan obyek yang sama dan berbeda sehingga dapat dibedakan antara obyek dalam cluster-cluster yang lain dan dapat diketahui keakuratan total jumlah produk (Stock Accuracy) yang ada didalam gudang.

\section{METODE PENELITIAN}

Metode penelitian merupakan prosedur/tahapan dan teknik penelitian. Antara satu penelitian dengan penelitian yang lain, prosedur dan tekniknya akan berbeda.

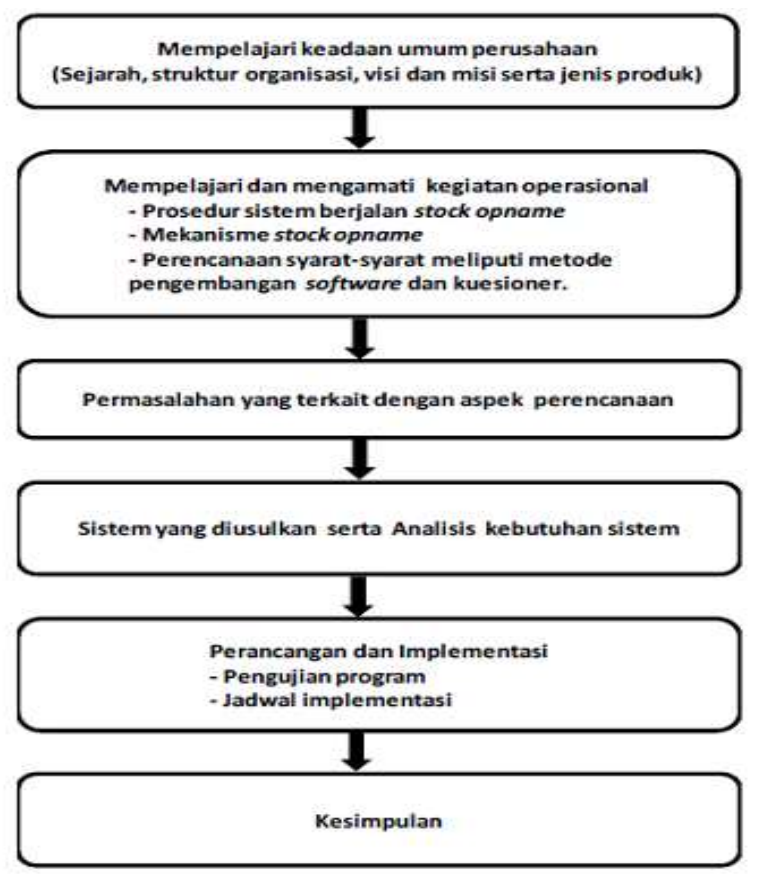

Gambar 1. Kerangka Penelitian

\section{HASIL DAN PEMBAHASAN}

\subsection{Perancangan UML}

Penggunaan komputer sebagai alat bantu penyelesaian pekerjaan di bidang teknologi sistem informasi kian marak dan berkembang di segala bidang. Komputer dirasa memiliki banyak keunggulan, diantaranya adalah dengan pengolahan data dengan metode yang terstruktur dimana data yang ada diolah menjadi suatu informasi yang penting bagi kebutuhan masyarakat atau instansi lainnya. Misalnya dalam kasus ini bagian inventory control di warehouse PT.Coca- Cola Amatil Indonesia Cibitung-Plant. Pada saat akan melihat data hasil stock opname tidak perlu membuka file-file sebelumnya alasannya data yang ada dapat diolah menjadi suatu kumpulan informasi yang berharga dalam proses komputerisasi dan lebih efektif dan efisen dalam mengambil keputusan.

Setelah melakukan analisa kebutuhan sistem, dan keinginan user sudah di dapatkan, maka tahap selanjutnya adalah menterjemahkan analisis ini ke dalam bentuk UML yaitu Use Case Diagram, Activity Diagram dan Class Diagram.

1. Use Case Diagram

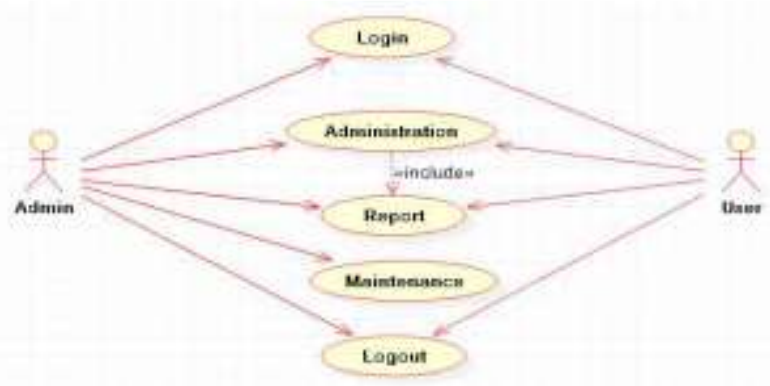

Gambar 2. Use Case Diagram 
JURNAL MEDIA INFORMATIKA BUDIDARMA

Volume 4, Nomor 1, Januari 2020, Page 72-81

ISSN 2614-5278 (media cetak), ISSN 2548-8368 (media online)

Available Online at https://ejurnal.stmik-budidarma.ac.id/index.php/mib DOI 10.30865/mib.v4i1.1795

2. Activity Diagram

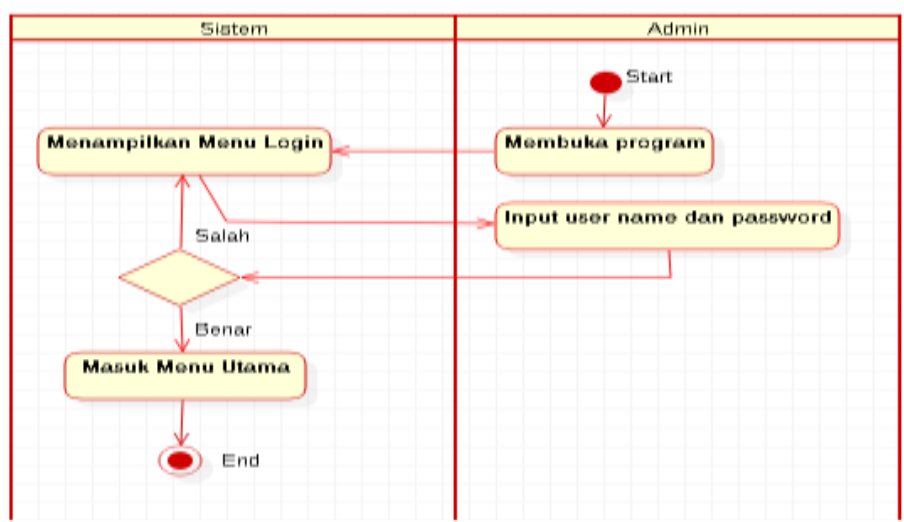

Gambar 3. Activity Diagram Login

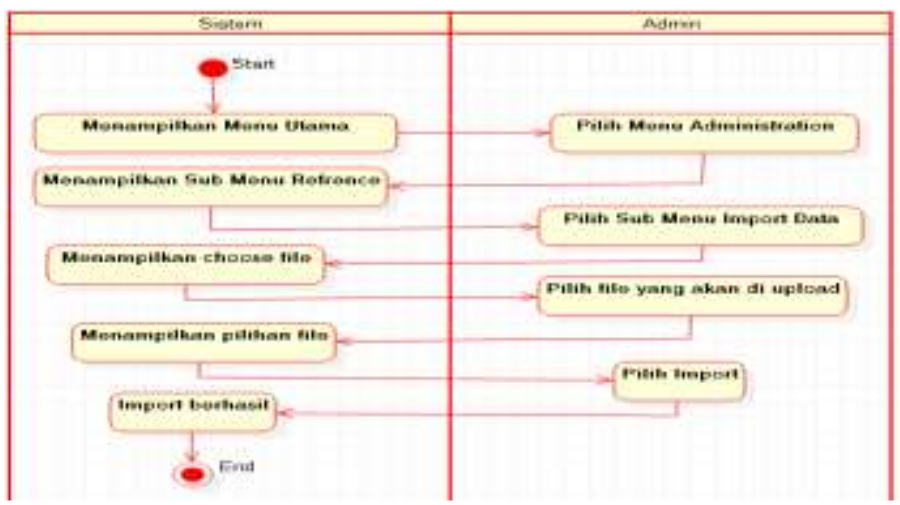

Gambar 4. Activity Diagram Administration

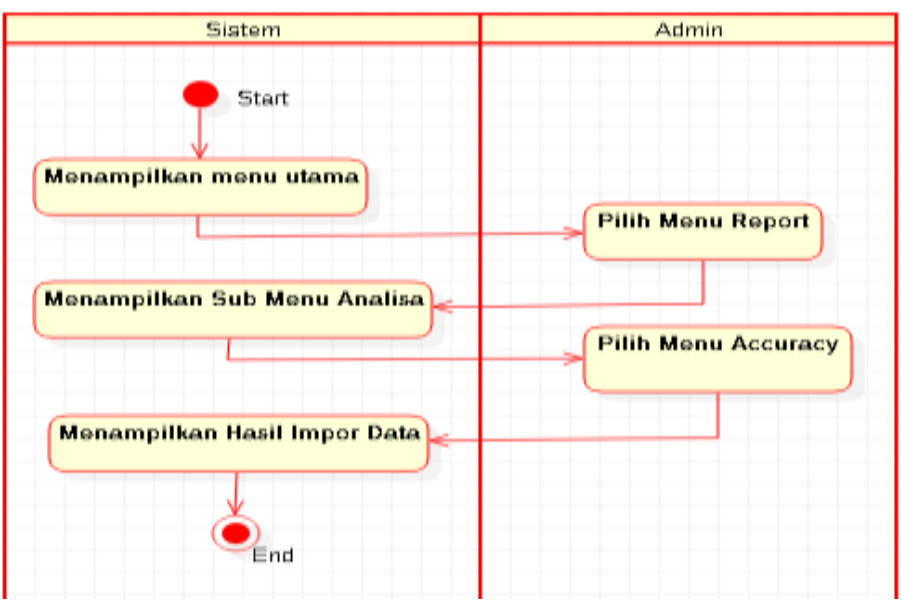

Gambar 5. Activity Diagram Report

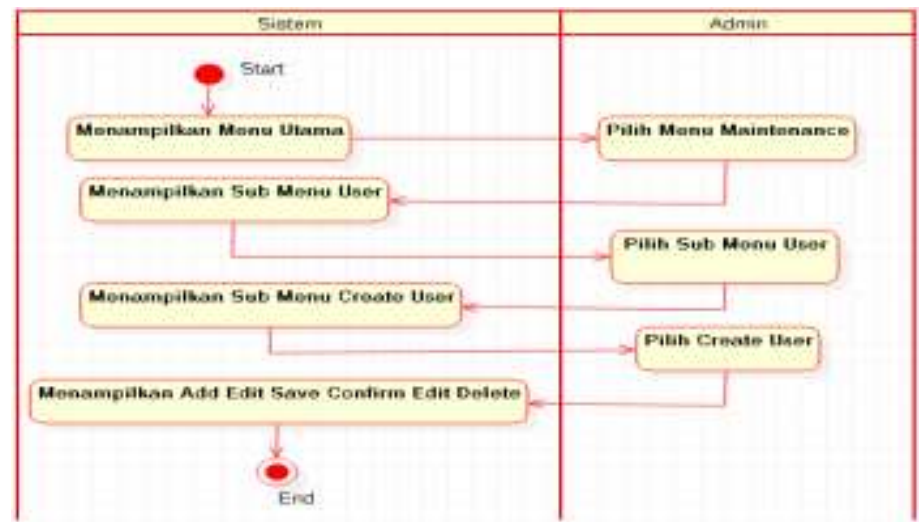

Gambar 6. Activity Diagram Maintenance 
Available Online at https://ejurnal.stmik-budidarma.ac.id/index.php/mib DOI 10.30865/mib.v4i1.1795

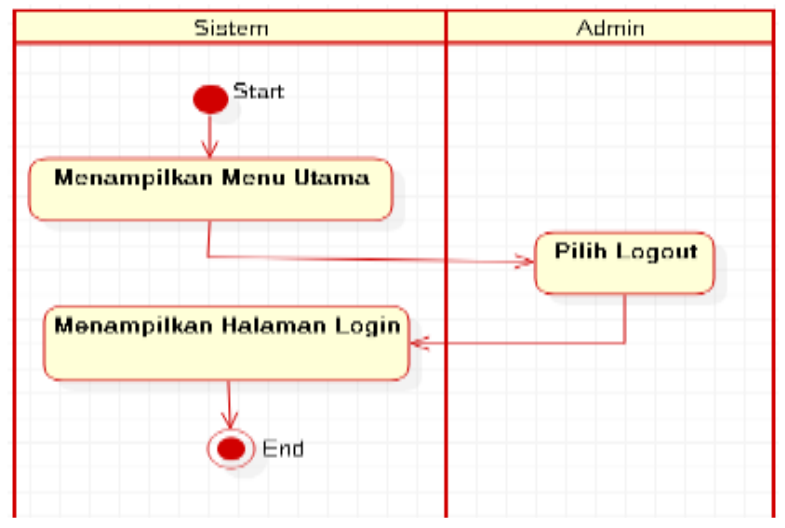

Gambar 7. Activity Diagram Logout

3. Class Diagram

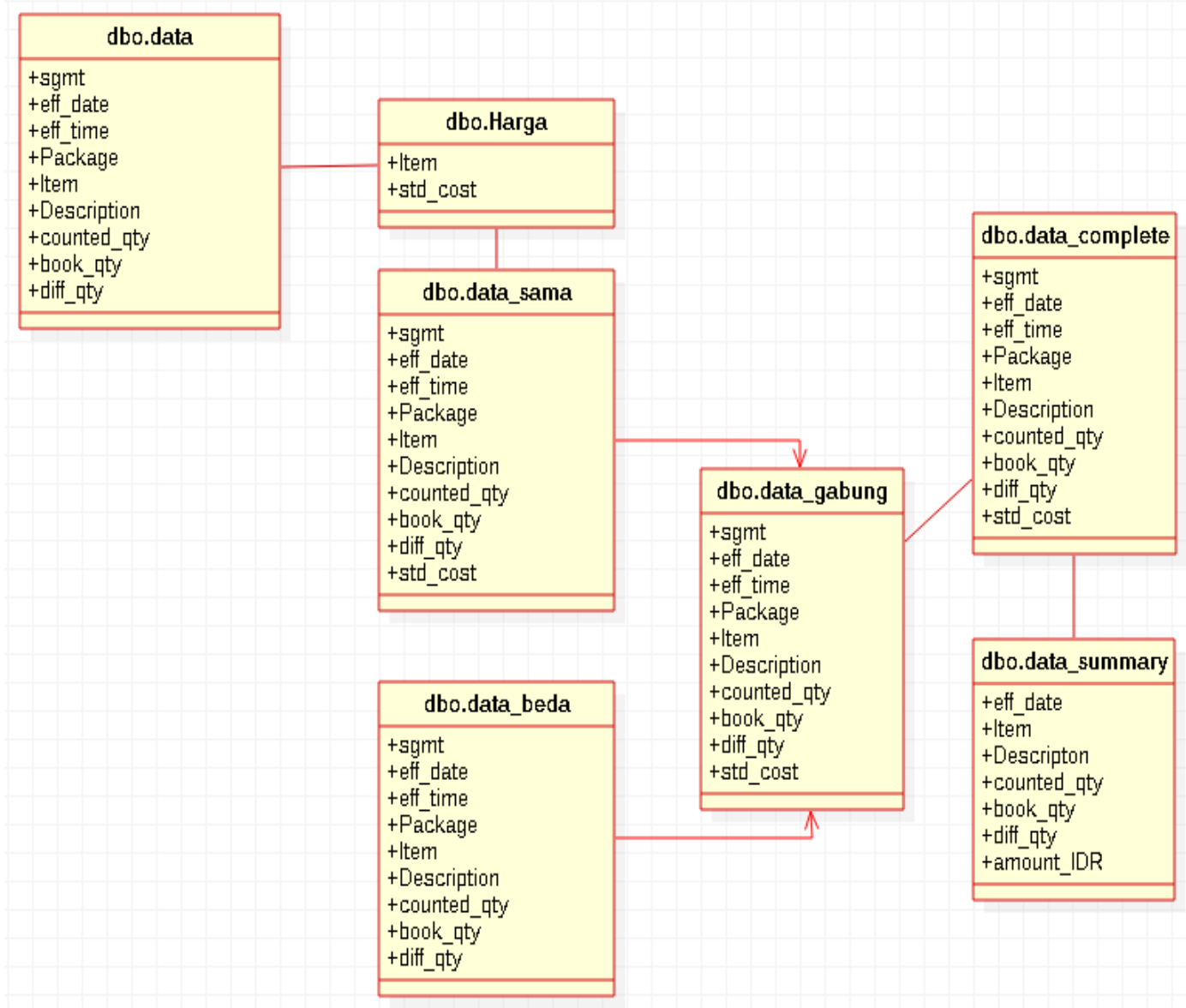

Gambar 8. Class Diagram

Sistem pengolahan data yang akan dibuat dikhususkan pada kebutuhan inventory control, dimana sistem usulan ini mengolah data hasil stock opname yang di export dari sistem WMS-Lucia berupa file CSV kemudian diimport kedalam sistem usulan, yang mana hasil import tersebut akan menampilkan stock accuracy yang meliputi stock system, stock fisik dan diffrence digudang. Hasil tersebut menjadi acuan untuk mengambil keputusan atas perlakuan diffrence yang ada. Dengan menggunakan teknik data mining dalam membuat program ini, bertujuan agar program dapat menampilkan informasi yang berguna bagi admin/user, dalam hal ini khususnya bagian inventory control yang menangani pergerakan stok di gudang.

\subsection{Proses Data Mining}

Pada tahap ini dalam mengolah data penulis mengunakan proses data mining, dimana data yang ada akan diolah menjadi suatu informasi yang berharga. Dalam pembuatan data mining ini ada tahapan-tahapan diantaranya proses import data, proses pembersihan, proses integrasi, seleksi data dan proses transformasi.

1. Proses Import Data 


\section{JURNAL MEDIA INFORMATIKA BUDIDARMA}

Volume 4, Nomor 1, Januari 2020, Page 72-81

ISSN 2614-5278 (media cetak), ISSN 2548-8368 (media online)

Available Online at https://ejurnal.stmik-budidarma.ac.id/index.php/mib DOI 10.30865/mib.v4i1.1795

Proses import data adalah proses dimana data dari hasil stock opname di export ke dalam program dengan format CSV.

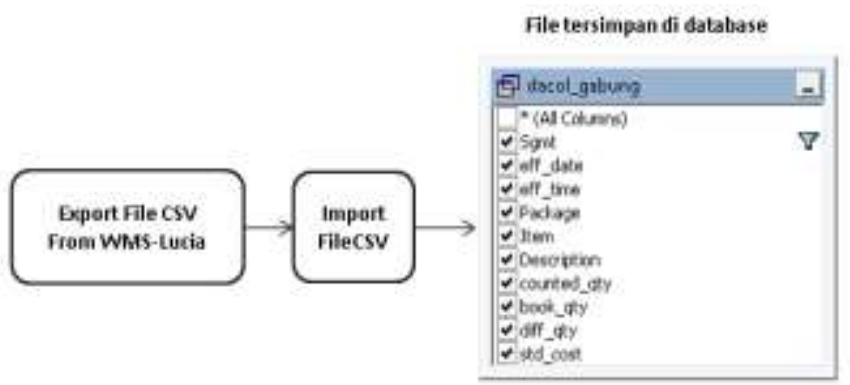

Gambar 9. Proses Import Data

Dari penjelasan gambar 9 diatas hasil stock opname di export dari WMS-Lucia kemudian data akan tersimpan dalam database SQL dengan detail, sgmt,eff_date, eff_time, Package_Item, Description, counted_qty, book_qty, diff_qty dan std_cost.

2. Proses Cleaning

Pada proses cleaning ini adalah untuk menghilangkan data yang tidak relevan.

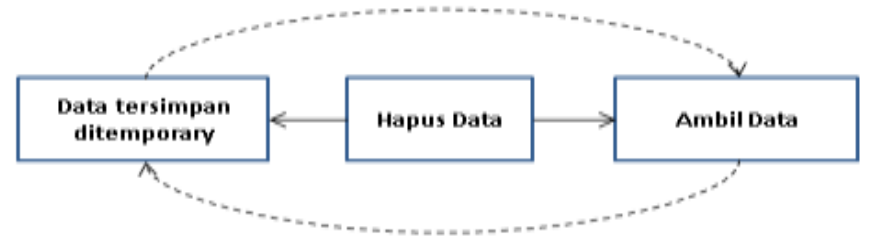

Gambar 10. Proses Cleaning

Dari penjelasan gambar 10 diatas dapat dijelaskan bahwa pada tahap ini semua data yang tersimpan didalam data temporary akan dibersihkan dari record, selain data yang tidak mempunyai record data yang tidak valid juga dibersihkan, hal ini berfungsi untuk performasi dari sistem data mining karena data yang ditangani akan berkurang jumlah dan kompleksitasnya.

3. Proses Integrasi

Proses integrasi merupakan penggabungan data dari berbagai database ke dalam satu database.

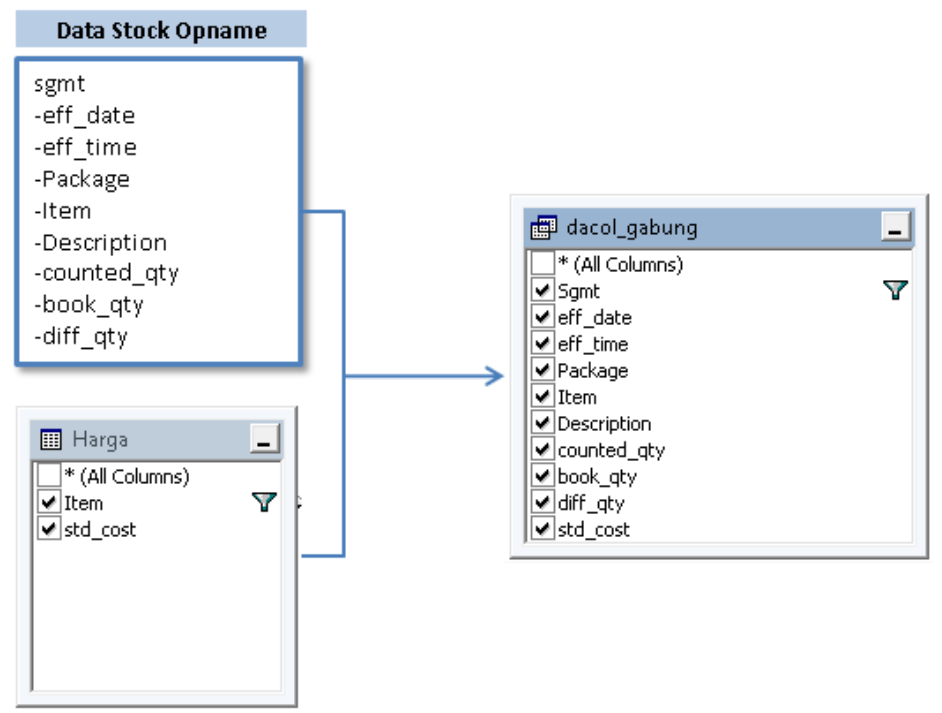

Gambar 11. Proses Integrasi

Dari penjelasan gambar 11 diatas proses integrasi yang terjadi adalah data stock opname dan data price digabungkan dalam satu database, penggabungan data ini berfungsi untuk mengidentifikasi data dengan satu atribut yang berbeda, dari data tersebut yaitu Item adalah unik dan std_cost adalah data gabungan baru.

4. Selection Data

Proses selection data merupakan proses menyeleksi attribute apa yang akan diproses pada mining selanjutnya. 


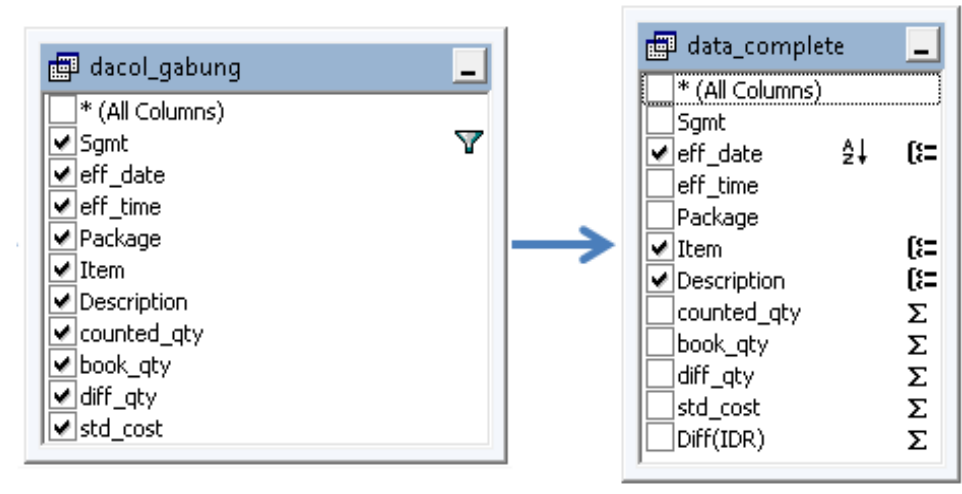

Gambar 12. Selection Data

5. Proses Transformasi

Proses transfromasi data merupakan proses mengubah data atau digabung ke dalam format yang sesuai untuk diproses dalam data mining.

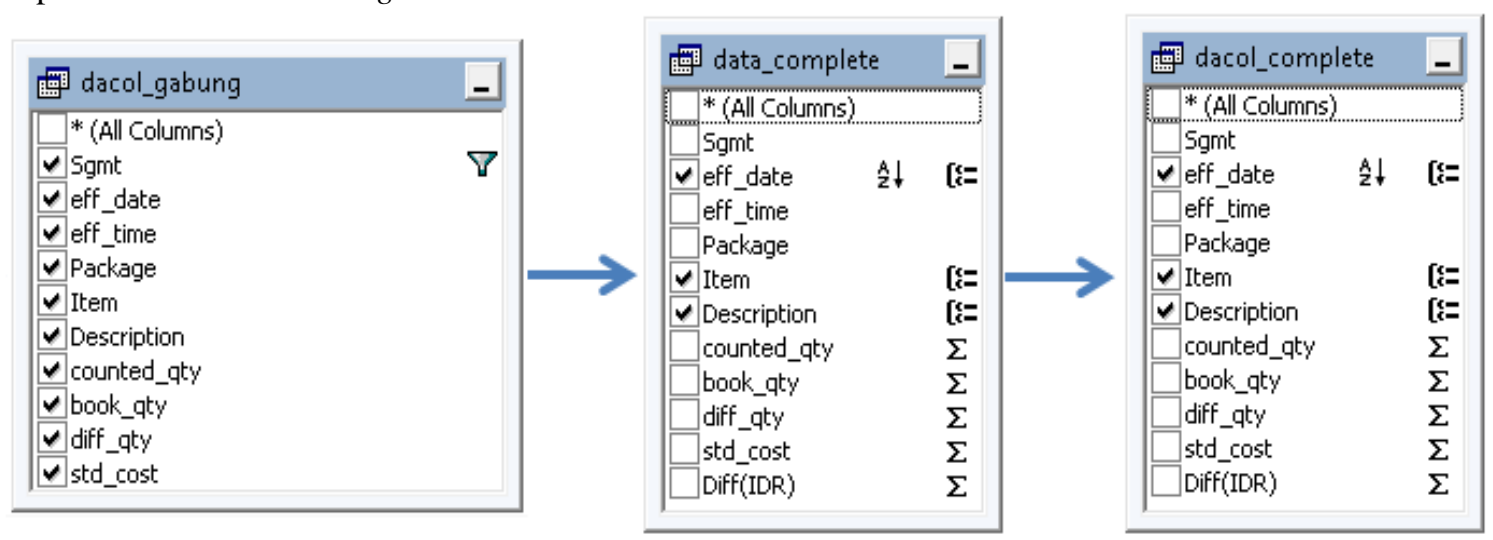

Gambar 13. Proses Transformasi

Dari penjelasan gambar 13 diatas proses transformasi data ini adalah tahap akhir dalam proses data mining, hasil yang akan ditampilkan berupa, eff_date, Item, Description, counted_qty, book_qty dan Amount_IDR.

\subsection{Implementasi Sistem}

Tahap implementasi sistem merupakan tahap menerjemahkan rancangan berdasarkan hasil analisa dalam bahasa yang dapat dimengerti oleh mesin serta penerapan pada keadaan yang sesungguhnya.

\subsubsection{Spesifikasi Sistem}

Dalam mengimplementasikan rancangan sistem yang baru, penulis menyertakan minimum peralatan pendukung yang terdiri dari perangkat keras (hardware) dan perangkat lunak (software) agar sistem informasi Data Mining ini bisa berjalan dengan lancar.

1. Perangkat keras (hardware) minimum yang digunakan, yaitu:

- Processor : Intel ® Celeron ® CPU B815@ $1.60 \mathrm{GHz}$

- Memory : 2 GB DDR3

- Hardisk : 320 GB HDD

- VGA : Intel ® HD Graphics

- CD ROM : PIONER

- Monitor : CRT14"

- Printer : EPSON LQ-2180 series

- Keyboard : PS/2 Standart

- Mouse : Optical

2. Perangkat lunak ( Software) yang digunakan, antara lain :

- Sistem Operasi : Ms. Windows 7 Ultimate

- Web Server : Xampp

- Database : SQL Server

- UML Diagram : Star UML

- Bahasa Pemrograman : PHP

- Editor : Dreamweaver

- Microsoft Office : Office 2010 
JURNAL MEDIA INFORMATIKA BUDIDARMA

Volume 4, Nomor 1, Januari 2020, Page 72-81

ISSN 2614-5278 (media cetak), ISSN 2548-8368 (media online)

Available Online at https://ejurnal.stmik-budidarma.ac.id/index.php/mib DOI 10.30865/mib.v4i1.1795

\subsubsection{Manfaat Sistem}

Manfaat dari sistem infromasi data mining ini adalah untuk membantu kinerja personil Admin Inventory Control dalam mengambil keputusan dari hasil stock opname, yang mana hasil stock opname akan menjadi acuan atas perlakuan difference yang ada.

\subsubsection{Implementasi Struktur Database}

Struktur Database merupakan data yang berhubungan satu dengan yang lainnya yang membentuk komponen yang penting dalam sebuah sistem dan dapat berfungsi sebagai informasi kepada para pemakainya, Database pada sistem informasi data mining mempunyai tugas inti sebagai berikut:

1. Menyimpan data produk yang diproduksi di PT. Coca-Cola Amatil Indonesia.

2. Menyimpan dan menampilkan data transaksi hasil stock opname sebelumnya.

3. Sebagai pembanding dalam proses mengolah data dan sistem akan menampilkan hasil perhitungannya. Oleh karena itu, penulis membuat sebuah Database yang terdiri dari beberapa tabel.

\subsubsection{Implementasi Antar Muka}

\section{Halaman Menu User}

Berikut tampilan halaman menu user

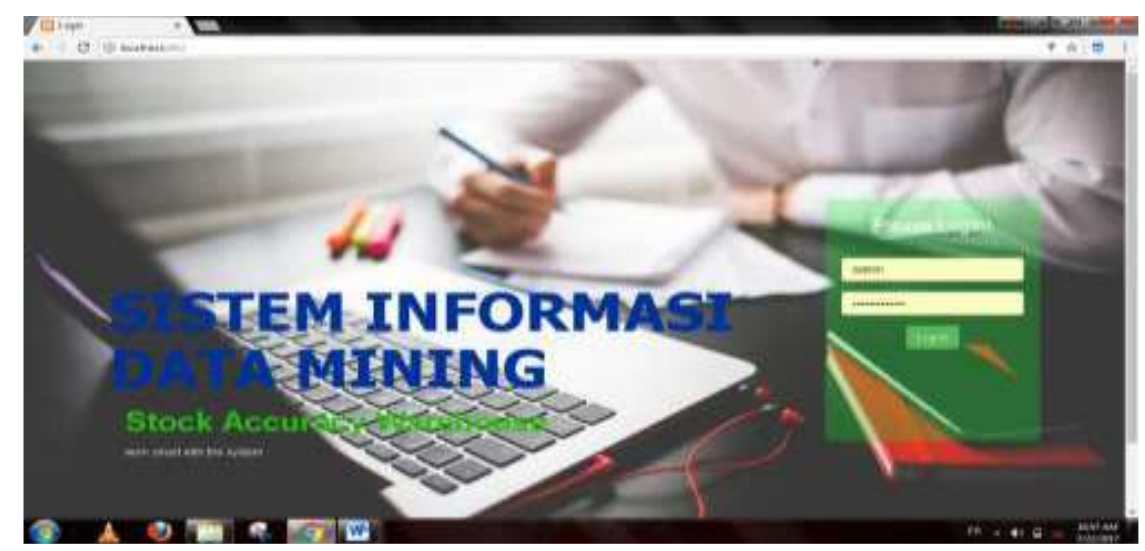

Gambar 14. Halaman Menu User

\section{Halaman Menu Utama}

Berikut tampilan halaman menu utama

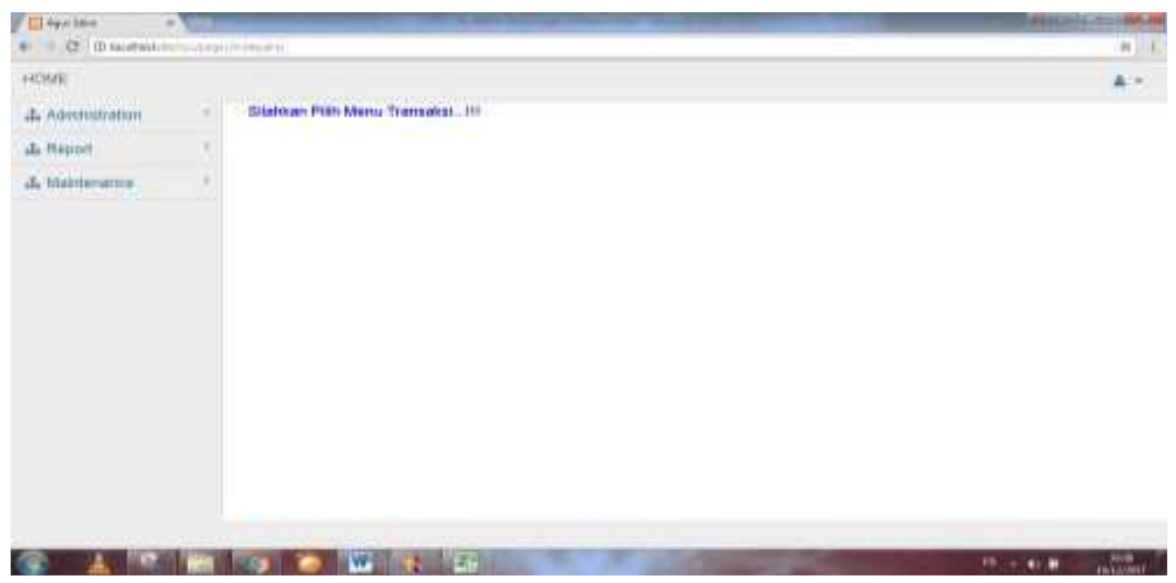

Gambar 15. Halaman Menu Utama

\section{Halaman Menu Admin}

Berikut tampilan halaman menu admin 
JURNAL MEDIA INFORMATIKA BUDIDARMA

Volume 4, Nomor 1, Januari 2020, Page 72-81

ISSN 2614-5278 (media cetak), ISSN 2548-8368 (media online)

Available Online at https://ejurnal.stmik-budidarma.ac.id/index.php/mib

DOI 10.30865/mib.v4i1.1795

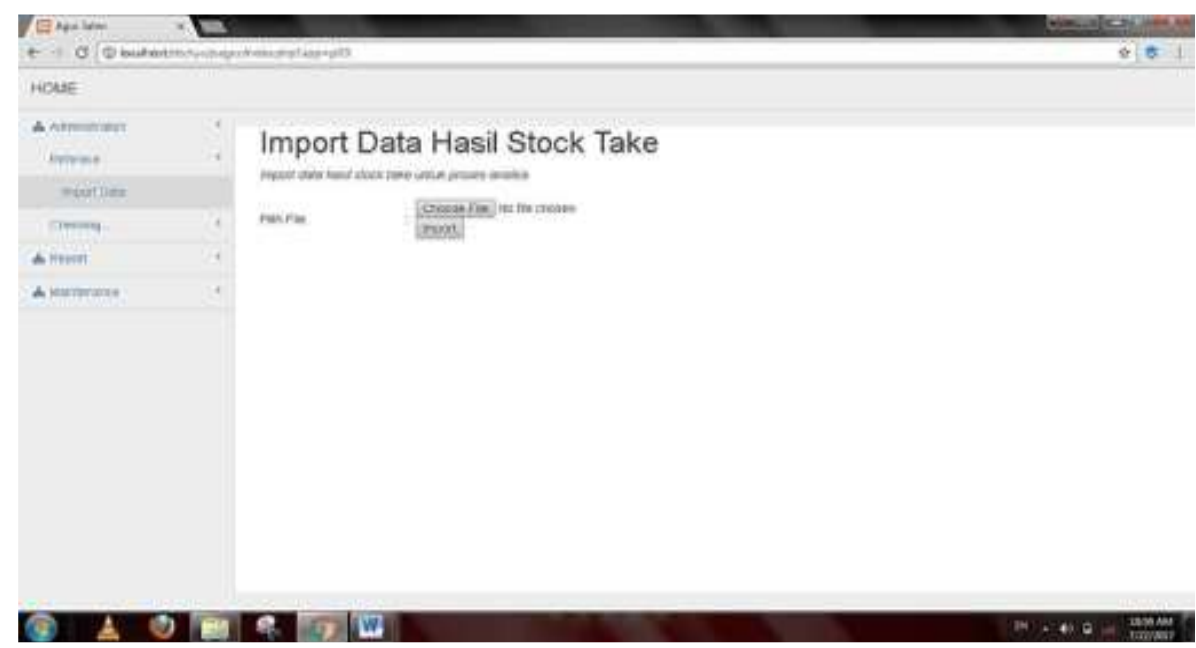

Gambar 16. Halaman Menu Admin

\section{Halaman Menu Import Data}

Berikut tampilan halaman import data

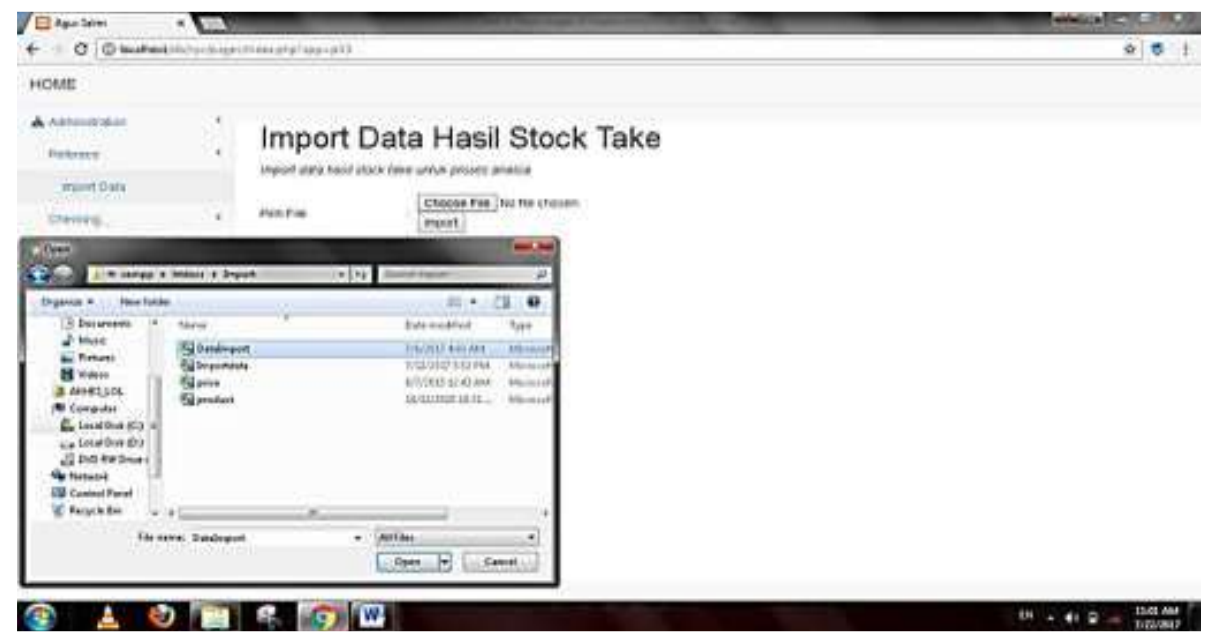

Gambar 17. Halaman Menu Import Data

\section{Halaman Menu Import Data Hasil}

Berikut tampilan halaman import data hasil

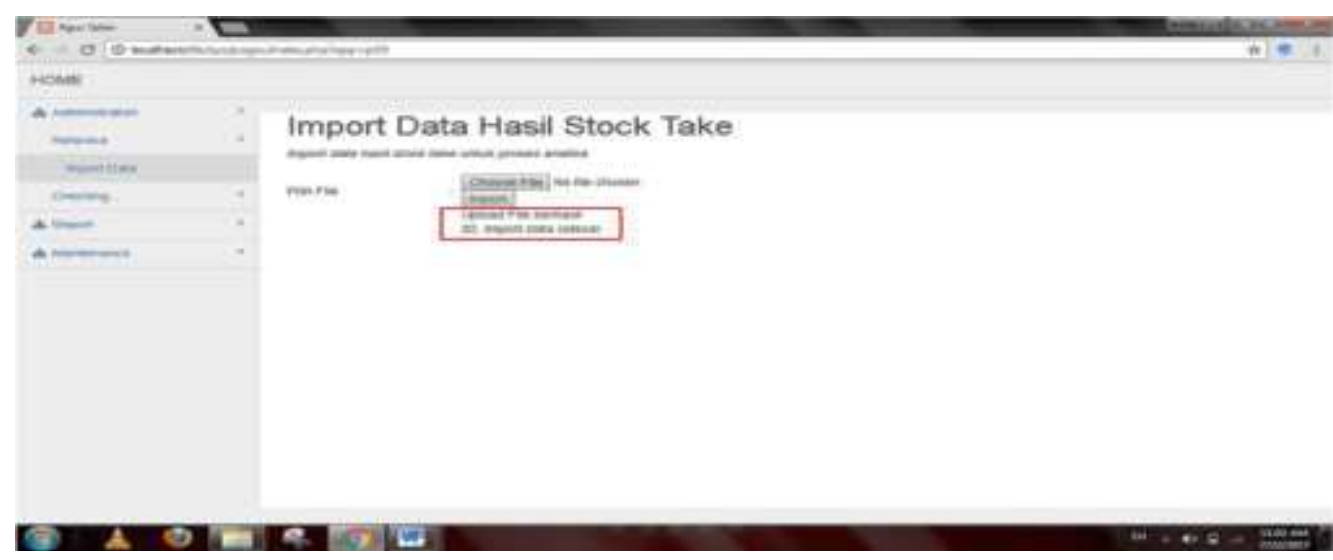

Gambar 18. Halaman Menu Import Data Hasil

\section{Halaman Checking data}

Berikut tampilan halaman checking data 
JURNAL MEDIA INFORMATIKA BUDIDARMA

Volume 4, Nomor 1, Januari 2020, Page 72-81

ISSN 2614-5278 (media cetak), ISSN 2548-8368 (media online)

Available Online at https://ejurnal.stmik-budidarma.ac.id/index.php/mib DOI 10.30865/mib.v4i1.1795

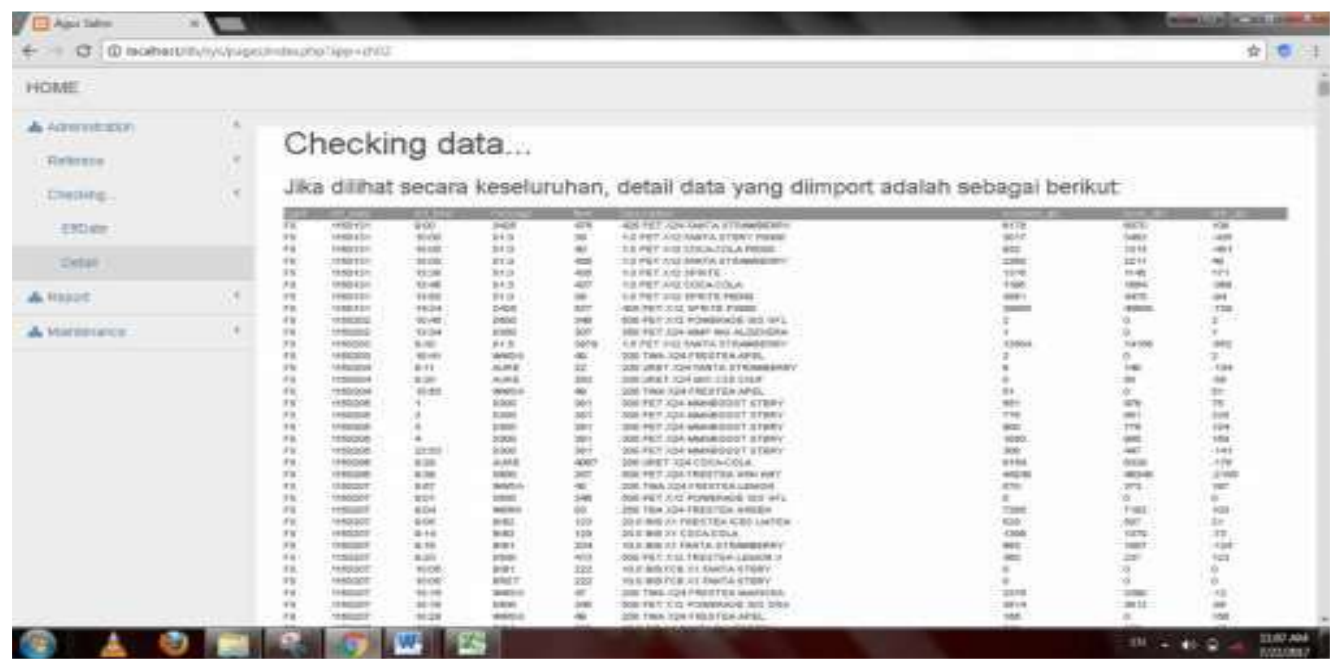

Gambar 19. Halaman Menu Detail

\section{Halaman Report}

Berikut tampilan halaman report

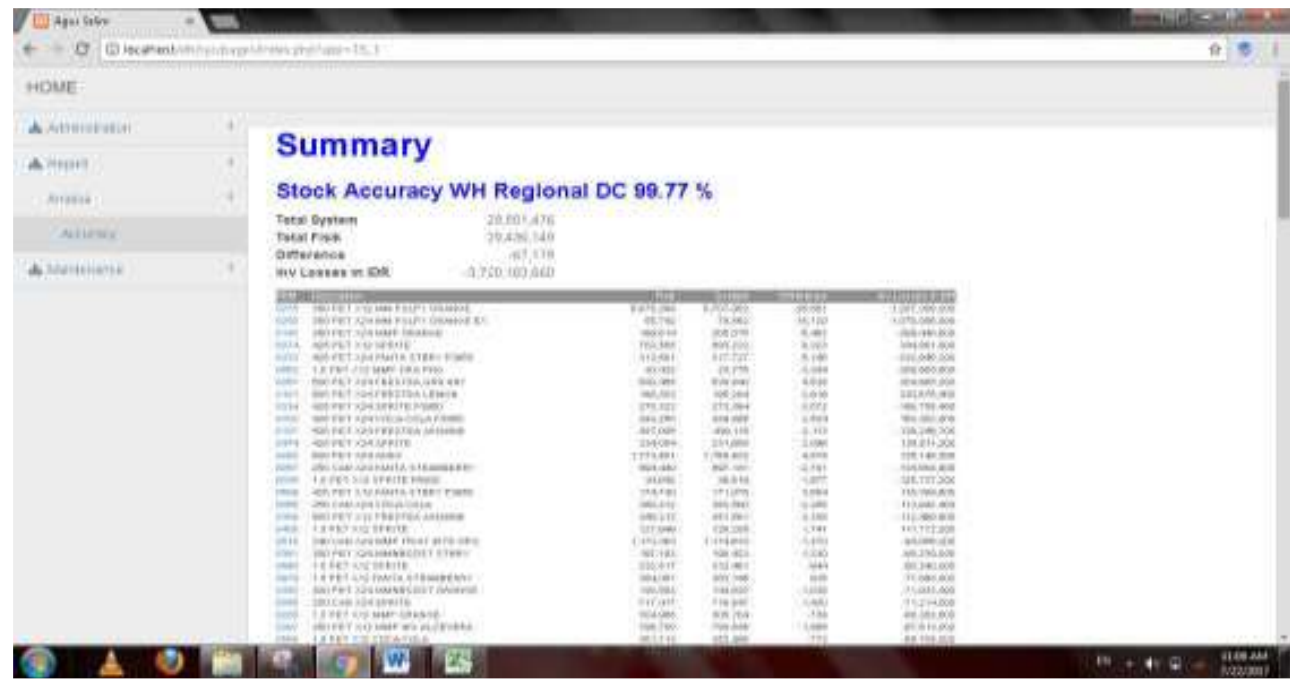

Gambar 20. Halaman Menu Report

\section{Halaman Summary}

Berikut tampilan halaman summary

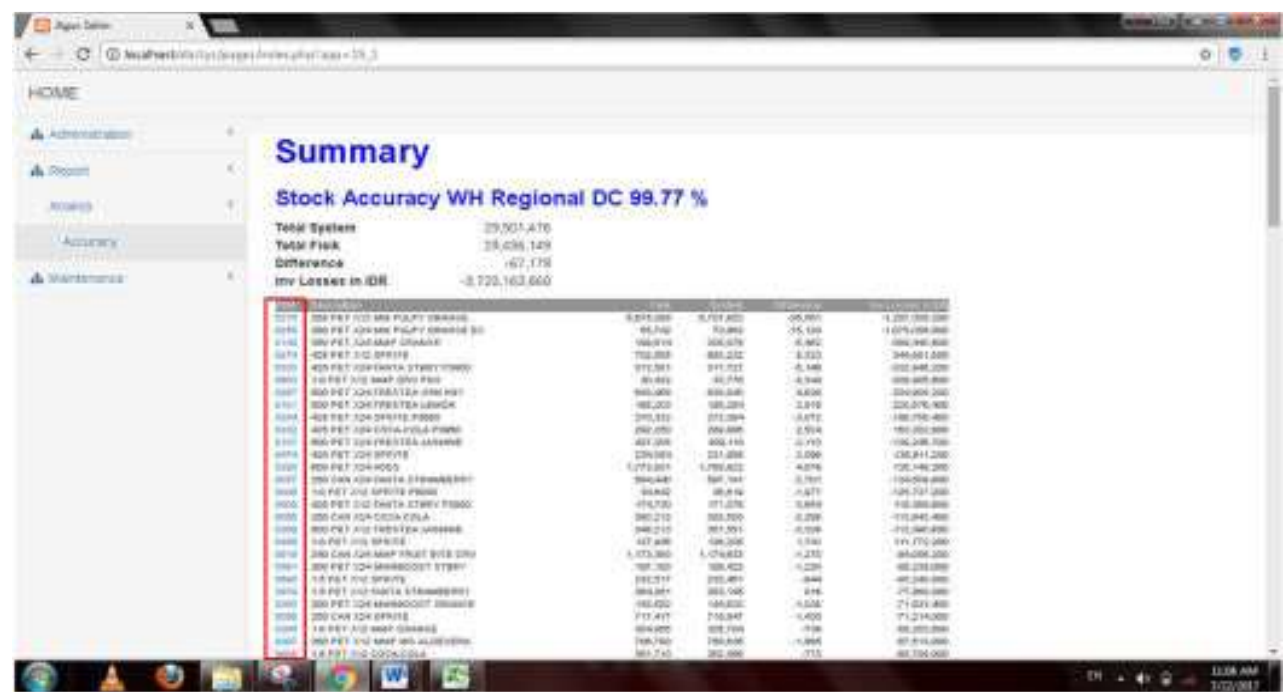


JURNAL MEDIA INFORMATIKA BUDIDARMA

Volume 4, Nomor 1, Januari 2020, Page 72-81

ISSN 2614-5278 (media cetak), ISSN 2548-8368 (media online)

Available Online at https://ejurnal.stmik-budidarma.ac.id/index.php/mib

DOI 10.30865/mib.v4i1.1795

Gambar 21. Halaman Menu Accuracy

\section{Halaman Maintenance}

Berikut tampilan halaman maintenance

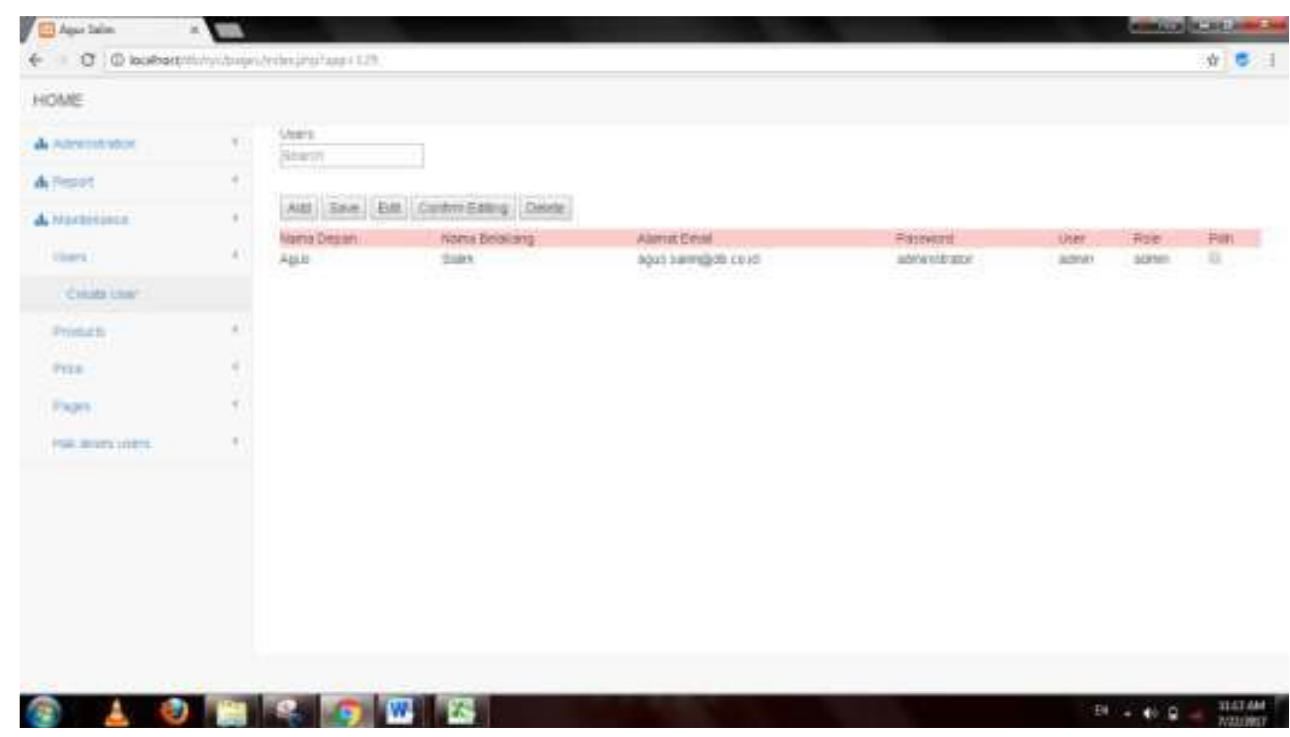

Gambar 22. Halaman Menu Maintenance

\section{KESIMPULAN}

Di PT. Coca-Cola Amatil Indonesia banyak sistem yang sudah diaplikasikan, namun belum memanfaatkan sistem komputer secara efektif dalam proses penghitungan jumlah produk untuk menentukan keakuratan jumlah stok yang ada di sistem dan yang ada dilapangan (Stock Accuracy). Dalam permasalahan proses keakuratan jumlah produk (stock accuracy) pendekatan menggunakan prinsip teknik data mining. Solusi yang diberikan sistem informasi data mining ini dapat memudahkan pengguna dalam mengambil keputusan pada proses penghitungan jumlah produk, dengan waktu yang lebih efisien tepat dan akurat. Dengan menggunakan sistem informasi Data Mining di PT. Coca-Cola Amatil Indonesia Cibitung-Plant maka permasalahan-permasalahan dapat ditekan seminimal mungkin karena sistem ini dapat menjadi acuan dalam mengambil keputusan untuk keakuratan jumlah produk di dalam gudang.

Diharapkan sistem informasi data mining ini dapat diimplementasikan dan digunakan oleh user yaitu personil Admin Inventory Control pada department WT-Regional DC di PT. Coca-Cola Amatil Indonesia Cibitung-Plant. Disarankan sistem aplikasi ini dapat dikembangkan sesuai dengan kebutuhan perkembangan perusahaan dan teknologi.

\section{REFERENCES}

[1] Agus Ristono, (2013), Manajemen Keuangan Teori dan Aplikasi, Edisi 4. BPFE- Yogyakarta.

[2] Elmasari, Ramez and Shamknat B. Navathe, (2012), Fundamentals of Database Systems, Third Edition, Addison Wesley Publishing Company, New York.

[3] Han, Jiawei, (2014), Data Mining : Concepts and Techniques, Department of Computer Science University of Illinois at Urbana-Champaign.

[4] Jindal, Rajni, and Taneja, Shweta , (2012), Comparative Study of Data Warehouse Design Approaches: A Survey.

[5] Jogiyanto Bukunya Yakub, (2012), Pengantar Sistem Informasi, Graha Ilmu, Yogyakarta.

[6] Kadir, Abdul, (2013), Pengenalan Sistem Informasi, Andi, Yogyakarta.

[7] Manari, J. I, (2013), Perancangan Basis Data Perusahaan Distribusi dengan Menggunakan Oracle, e-journal.

[8] Moh. Nazir Ph D, (2014), Metode Penelitian, Ghalia Indonesia, Bogor.

[9] Rainardi, Vincent, (2013), Building a Data Warehouse with Examples in SQL Server, Springer, New York.

[10] R. Ramakrishnan and J. Gehrke, (2007), Database Management System, McGraw Hill Higher Education, USA.

[11] Santoso, Budi, (2007), Data Mining Teknik Pemanfaatan Data Untuk Keperluan Bisnis, Graha Ilmu, Yogyakarta.

[12] S, Rosa A. dan M.Shalahudin, (2013), Rekayasa Perangkat Terstrtuktur Dan Berorientasi Objek, Informatika, Bandung.

[13] Witten, I. H and Frank, E, (2011), Data Mining: Practical Machine Learning Tool and Techniques Second Edition,Morgan Kauffman:San Francisco. 